\title{
Contributions of Workflow and Information Flow Studies to Clinical Information Retrieval in Radiology Environments
}

\author{
M. dos-Santos \\ Dept of Librarianship and Documentation at School \\ of Communications and Arts, Univ. of Sao Paulo \\ Av. Prof. Lúcio Martins Rodrigues, 443, rm 257 \\ 05508-020, Sao Paulo-SP, Brazil
}

\author{
J. E. da Rocha \\ Pref. Munic. de São Paulo, Sec. Mun. da Cultura \\ Rua Catão, 611, 6a andar \\ Vila Romana
}

\begin{abstract}
This paper proposes elements for the effective design and implementation of specialized information systems, specifically those, which are used by professionals from different specialties and with different perspectives for the use of information. The paper is based on an analysis of the information flow in a radiology department. It poses reflections about clinical information retrieval systems based on principles of sharing and use of information scattered in specific subsystems, in order to guarantee the necessary infrastructure for the medical teams to have access to information in real time to make integrated analyses of the clinical state of patients. This investigation is made by using the theoretical framework of Information Science, especially the information cycle, as well as the principles of organization proposed by Information Architecture. The results indicate the need to think about mechanisms for the information management, which should take into account aspects of interoperability of documents and information of different natures, generated in heterogeneous environments. It is possible to conclude that clinical documents are in a constant state of elaboration. Because of this, it requires specific actions in terms of the project and management of information services that deal with documents of such nature.
\end{abstract}

\section{General Terms}

Clinical workflow, information retrieval, radiology.

\section{Keywords}

Information in Health; Clinical Information; Information Management in Electronic Environments; Information Retrieval System.

\section{INTRODUCTION}

Patient care delivery is traditionally performed by a group of professionals (different actors in different offices: consultation rooms, waiting rooms, exam rooms, and technical work areas), requiring multidisciplinary collaboration. In health care organizations, the process by which tasks are done, by whom, in what order and how quickly is named clinical workflow [1][2]. It refers to systems that help to specify, execute, monitor, and coordinate accomplishment of tasks[3]. Taking into account that the information flow comprises the processes of production, transfer, and use of information, each health care institution has an information flow which is specific, based on the development of its daily activities. Inasmuch as, clinical workflow is designed with the purpose of facilitating communication in a collaborative environment and assisting team members who work together and accomplish complex tasks[1].

Clinical workflow is often characterized in terms of action patterns employed by clinical staff to perform routine tasks and generate results[1]. It considers elements like [4] assumptions, values and norms that people have about creating, sharing and using clinical information. These elements shape the health care organization's perception, management and use of clinical information. In general, a clinical workflow encompasses a range of tasks, usually performed by the referring physician, such as (based on[1]): (1) record the patient's history, (2) perform an examination, (3) choose appropriate diagnostic studies, (4) make a diagnosis, (5) decide on a course of action, (6) provide patient education, (7) in some cases prescribe medication and (8) perform clinical follow-ups.

In spite of the advances and developments of clinical information systems, generally speaking, health care institutions still face difficulties to produce, manage, make available, and access information that is relevant to the execution of their tasks.

In the case of medical radiology, clinical information is found scattered in the following information systems[5]: (a) hospital information systems, (b) radiology information systems, and (c) image storage and communication systems.

Images, medical reports (the documents that summarize the clinical conditions observed in the exams) and medical records represent sources of information both for health care procedures and for educational and research activities. These sources, existing in an environment which uses information and communication technologies (ICTs), offer the potential for the creation of products and services which may facilitate the development of teaching practices such as the development of electronic learning environments in radiology $[6,7]$. In such products, the task of information retrieval is involved. However, information retrieval from the databases of clinical documents which comprise the clinical information system has been a costly and sometimes inefficient process, even though the users of this system employ ICT-based tools.

In order to offer better conditions for the retrieval of clinical information from the information systems databases and to carry out management studies in electronic environments, this paper presents the analysis of the information flow of a radiology department, compares it to the information cycle [8- 
10] and relates it to the contributions offered by Information Architecture [11], with the goal of implementing information management actions.

\section{THEORETICAL FRAMEWORK}

With the development of electronic computing in the $20^{\text {th }}$ century, the first generation of information retrieval systems (IRS) based on computing resources came into existence, the objective of which was to automate information retrieval operations. Since then, IRS evolved to their second and third generations, using the available resources in each era, such as graphic interfaces, indexing languages, search resources and strategies, information representation, and focus on the user's needs, with the objective of becoming more flexible, dynamic, precise, and easier to operate $[12,13]$.

Recently, natural language processing-based (NLP) approaches have come into use, with the goal of improving information retrieval by using computer algorithms to analyse and process the information found in clinical texts (especially in unstructured texts) [14].

There have been efforts from societies such as the American College of Radiology to create mechanisms that can help radiological information retrieval. Standing out among them is the creation and perfecting of controlled vocabularies and ontologies like Radlex, for the treatment of the information content of medical reports [15].

Other studies report techniques of data mining [12] and extraction of the characteristics of an image so as to make possible the retrieval of images based on their content (Content Based Image Retrieval - CBIR) [7].

Notwithstanding all these initiatives, many of which have been successful, Müller et al [7], in their review article about CBIR, point to the need for information flow studies, aiming at the development of search interfaces adapted for specific purposes.

The information cycle [8-10] is studied and used to optimise access to and use of information, identifying and enhancing information resources. In the study of the information cycle, it is also possible to identify and investigate the processes of generation, selection/acquisition, representation, storage, retrieval, distribution, and use of information [8-10].

In a complementary approach to the study of the information cycle, Information Architecture, initially conceived to represent and retrieve information in information systems and websites, has provided conditions to (re)think humanmachine-content interaction by means of proposals for the structuring, organization, markup, representation, and planning of the provision of information, so that users may find it more easily [16]. In short, for Rosenfeld and Morville [11], Information Architecture comprises the following elements: organization system; tagging system; navigation system; search system.

\section{MATERIAL AND METHODS}

For the development of this study, it has set off from the assumption that the clinical environment offers an opportunity to reflect on the conception and management of specialized information services in electronic environments, since this kind of environment is used by professionals from different specialties, all of whom have interests in clinical information, but with different perspectives for the use of the clinical documents generated digitally, as it can observed in this study. Development activities were grouped into three main steps, described further ahead.

The study was initiated with a bibliographic review (first step) - in this case a selective review with the objective of learning about some of the experiences and proposals that have been applied in the development of tasks related to the retrieval of clinical information. The literature reviewed comprises sources published from January 2003 to March 2010, a period which covers the investigations about this topic for the last years, obtained from searching the following databases SciELO.ORG, ScienceDirect (Elsevier), SpringerLink (MetaPress), Wiley InterScience (Blackwell), Library and Information Science Abstracts, Wilson Applied Sciences Abs \& Full Text, Library Information Science \& Technology Abstract, and Lilacs. As keywords in the search, the following descriptors were used: medical report, information retrieval, radiology report, radiography, retrieval system, teaching file, and information system.

After the review, study and organization of the materials thus obtained, it has started the analysis of the clinical environment under study (second step). Based on the standard flow of information of a radiology department [5], this analysis had three main objectives: (1) to understand the nature of the information present in this environment (such information is the input for the execution of several activities); (2) to identify the actors in this environment; and (3) to analyse the processes of generation and use of clinical information in this environment, in the light of what is proposed in the information cycle [8-10]. The execution of the first two tasks allowed us to understand in a comprehensive manner the information flow and the inter and intradepartmental relations. From this understanding, it was possible to identify and investigate the processes of generation, selection/acquisition, representation, storage, retrieval, distribution, and use of clinical information.

These results of the second step were the point of departure for the third step, which started with the study and application of the concepts of Information Architecture [11], with the aim of proposing of a document structure, which could circulate through the different information systems existent in the environment we studied. It is presupposed that this same structure could make possible the retrieval and use of information by the different actors, according to their specific contexts and needs.

\section{RESULTS}

The study undertaken in this research, complemented with considerations by professionals involved with the activities of a real clinical environment, shows evidence that part of the solution to the problems of information retrieval entails the study and workflow mapping, focusing on the information flow and the relations between the existing actors and their information needs.

Keeping this in mind, and proceeding with an analysis of the processes of generation and use of clinical information, the result that stands out is the set of requirements which need to be considered in the project and implementation of the interfaces of clinical information retrieval systems. Moreover, another set of requirements was elicited to facilitate the circulation of information among the different computer applications found in a radiology department. 
Based on this study of the information flow and supported by the concepts of Information Architecture, a standardized model was proposed to fulfil the information demands of the users. This model follows the specifications of international organizations and is structured and described using markup language, the Extensible Markup Language (XML), including a structure that allows for the use of controlled vocabularies and specific, standardized terminologies of medical radiology.

\section{DISCUSSION AND CONCLUSION}

Based on the study of the information flow in radiology department, it was possible to observe that clinical documents are continuously constructed in each interaction with the different services found in this environment. In this case, each interaction represents an event and each event, on its turn, generates and adds a new piece of information to the clinical document.

It could be noted that clinical documents are in constant elaboration, which requires customised actions in terms of the project and management of information services that deal specifically with this kind of document. Another aspect that was considered is that of interoperability, which is why it had been used the concepts of Information Architecture. It is necessary to ensure not only syntactic, but also semantic interoperability of the documents.

To sum it up, the construction of medical knowledge depends on the collective experience of a community. In the case of the medical area, knowledge is often built by means of previous experiences, and thus well-managed information may bring about and transform knowledge, which can guide actions. However, this transformation into knowledge depends on actions involving the management of information resources, tools, and ICTs, information policies and standards which constitute an infrastructure for the proper management of information. In this study, special attention is brought to issues concerning the interoperability of clinical documents and information in management activities.

\section{ACKNOWLEDGMENTS}

This work was supported by a grant (2010/19632-9) from São Paulo Research Foundation (FAPESP), Brazil.

\section{REFERENCES}

[1] Lee, J., Shartzer, A. 2005. Health IT and workflow in small physicians' Practices. NIHCM Foundation, Apr. 2005. Available at http://www.nihcm.org/pdf/AHRQQandA.pdf. Accessed on Jul. 01, 2014.

[2] Ozkaynak, M. et al. 2013. Patient-centered care requires a patient-oriented workflow model. J Am Med Inform Assoc, vol. 20, e1 (Jun 2013): e14-e16.

[3] Ellis, C.A. Workflow technology. In: Beaudouin-Lafon, M. Computer Supported Co-operative Work. John Wiley \& Sons, Chichester, 1999.
[4] Choo, C.W. 2013. Information culture and organizational effectiveness. Int. J. of Inform. Manage, vol. 33, no. 5, (Oct 2013) 775-779.

[5] Integrating the Healthcare Enterprise (September 06, 2013). IHE Radiology (RAD) Technical Framework Volume 1: IHE RAD TF-1 Integration Profiles. Available http://www.ihe.net/uploadedFiles/Documents/Radiology/ IHE_RAD_TF_Vol1.pdf. Accessed on Jul. 10, 2014.

[6] Santos, M., Furuie S.S. (2008) Proposta de um Ambiente Colaborativo para Suporte a Atividades de Educação em Radiologia Médica. In Anais do XI Congresso Brasileiro de Informática em Saúde (CBIS' 2008).

[7] Müller, H. et al. 2004. A review of content-based image retrieval systems in medical applications - clinical benefits and future directions. Int J Med Inform., vol. 73, no. 9, (Feb 2004)1-23.

[8] Choo, C. W. A Organização do Conhecimento. Editora SENAC, 2003.

[9] Ponuan Dante G. Sistemas de información. In: Sistemas de informción: principios y aplicaciones. La Havana, 2004.

[10] Tarapanoff, K. Informação, Conhecimento e Inteligência em corporações: relações e complementos. In: Tarapanoff, K. (Org.) Inteligência, informação e conhecimento. IBICT, 2006.

[11] Rosenfeld, L., Morville, P. Information Architecture for the World Wide Web. O'Reilly, 1998.

[12] Baeza-Yates, R., Ribeiro-Neto, B. Modern Information Retrieval. ACM Press Harlow, England, AddisonWesley, 1999.

[13] Rowley, J. A biblioteca eletrônica. Briquet de Lemos,Brasília, 2002.

[14] Denny, J.C., Bastarache, L., Sastre, E.A., Spickard, A. (2009) Tracking medical students' clinical experiences using natural language processing. J Biomed Inform, vol. 42, no. 5, (Oct. 2009) 781-789.

[15] Kundu, S. et al. (2009) The IR Radlex Project: an interventional radiology lexicon--a collaborative project of the Radiological Society of North America and the Society of Interventional Radiology. J Vasc Interv Radiol., vol. 20, suppl. 7, (Jul 2009): S275-S277.

[16] Davenport, T.H. Ecologia da Informação: porque só a tecnologia não basta para o sucesso na era da informação. Larence Prusak, São Paulo, 1998. 